\title{
Characterization of a complex near-surface structure using well logging and passive seismic measurements
}

\author{
Beatriz Benjumea, Albert Macau, Anna Gabàs, and Sara Figueras \\ Institut Cartogràfic i Geològic de Catalunya, Parc de Montjüic, 08038 Barcelona, Spain \\ Correspondence to: Beatriz Benjumea (beatriz.benjumea@icgc.cat)
}

Received: 26 January 2016 - Published in Solid Earth Discuss.: 4 February 2016

Revised: 5 April 2016 - Accepted: 6 April 2016 - Published: 27 April 2016

\begin{abstract}
We combine geophysical well logging and passive seismic measurements to characterize the near-surface geology of an area located in Hontomin, Burgos (Spain). This area has some near-surface challenges for a geophysical study. The irregular topography is characterized by limestone outcrops and unconsolidated sediments areas. Additionally, the near-surface geology includes an upper layer of pure limestones overlying marly limestones and marls (Upper Cretaceous). These materials lie on top of Low Cretaceous siliciclastic sediments (sandstones, clays, gravels). In any case, a layer with reduced velocity is expected. The geophysical data sets used in this study include sonic and gamma-ray logs at two boreholes and passive seismic measurements: three arrays and 224 seismic stations for applying the horizontal-to-vertical amplitude spectra ratio method $(\mathrm{H} / \mathrm{V})$. Well-logging data define two significant changes in the $P$-wave-velocity log within the Upper Cretaceous layer and one more at the Upper to Lower Cretaceous contact. This technique has also been used for refining the geological interpretation. The passive seismic measurements provide a map of sediment thickness with a maximum of around $40 \mathrm{~m}$ and shear-wave velocity profiles from the array technique. A comparison between seismic velocity coming from well logging and array measurements defines the resolution limits of the passive seismic techniques and helps it to be interpreted. This study shows how these low-cost techniques can provide useful information about near-surface complexity that could be used for designing a geophysical field survey or for seismic processing steps such as statics or imaging.
\end{abstract}

\section{Introduction}

Variation of near-surface seismic properties has a significant influence on seismic reflection quality. Differences in sediment thickness overlying hard rock or the presence of high-velocity layers (HVL) produce strong statics and energy attenuation. Such HVL can act as a barrier for seismic energy and dramatically affect seismic signal penetration. For this reason, characterization of low-velocity structures under high-velocity layers are poorly achieved by conventional seismic reflection processing. Well-known cases of high-velocity structures are salt bodies (Martini and Bean, 2002) or basalt layers (Flecha et al., 2011).

Near-surface carbonate rocks are an example of highvelocity layers. Since cementation can add stiffness to shallow carbonate rocks, increasing the elastic moduli and hence velocity, velocity inversions with depth are common (Eberli et al., 2003). On the other hand, many carbonates contain a small amount of insoluble components (e.g. clay minerals or organic matter). These components reduce the velocity in carbonates if they are more than $5 \%$ of the rock weight. Thus if the clay content of carbonates increases with depth, we find an additional origin for a decrease in velocity with increase of depth. Shallow carbonates also present karstic surfaces which are usually filled with unconsolidated sediments, adding more complexity to the near-surface region. In any case, subsurface architecture mapping with the seismic reflection method requires a good-quality shallow-velocity structure for static correction performance. Detailed nearsurface models are usually obtained from high-density borehole information or velocity models derived from seismic tomography and/or first arrival inversions (Bridle et al., 2006; Ogaya et al., 2016). 
The study area of this work is located in Hontomin (Burgos, Spain). This site has been the target for oil exploration during the early 1970s. For that purpose, four boreholes were drilled between late 1960s and 2007 (H1, H2, H3 and H4 in Alcalde et al., 2014). Currently, new interest has been motivated in the Hontomin site for the geological storage of $\mathrm{CO}_{2}$ due to the presence of a deep saline aquifer. Different geophysical methods have been used for geological characterization of the deep structures (Ogaya et al., 2014; Alcalde et al., 2014). The near-surface geology of this site is quite complex. It includes irregular topography, surficial unconsolidated sediments in some areas and is combined with carbonate outcrops in others. In addition, velocity inversion in carbonate rocks is expected as previously discussed.

This paper focuses on the application of inexpensive methods (passive seismic based on seismic noise analysis) supported by well-logging techniques as a good way of obtaining a detailed near-surface model. In particular, the objective of this study is to obtain a sediment map thickness of the study area, seismic characterization of carbonates and underlain sediments. This information can be used for modelling to address seismic survey design in such a complex area. It can also partially help to correct statics by providing bedrockdepth values.

\section{Geological setting}

The study area is part of the North Castilian Platform located in the southern sector of the Basque-Cantabrian domain, north of the Ebro and Duero basins and approximately $10 \mathrm{~km}$ north of the Ubierna Fault. The North Castilian Platform was formed during the Mesozoic extensional phase (Roca et al., 2011). During this period, the basin was filled in by a thick sedimentary sequence (Quesada et al., 2005). The tectonic context changed at the end of the Cretaceous period, producing the basin deformation during the Pyrenees orogeny (Muñoz, 1992).

From a stratigraphic point of view, the sequence studied in this work starts with the Lower Cretaceous sediments (Purbeck facies) formed by clays, sandstones and carbonates. They have a marine-continental origin and are covered by a continental sequence including Weald facies, Escucha and Utrillas Formations. (Quintà, 2013). They consist of alternating siliciclastic sediments (sands/gravels, low-cemented sandstones and clays). The sequence ends with Upper Cretaceous limestones, as Lower and Upper Cretaceous marls, limestones and calcarenites outcrop in the area (Fig. 1). In addition, Miocene and Quaternary sediments, including conglomerates, sands and clays, cover bedrock in some sectors.

A priori, near-surface geology complexity is expected since the topography changes from Quaternary plains to carbonate outcrops. On the other hand, buried bedrock topography is suspected to be highly irregular due to the karstic processes common in limestones. Hence, near-surface sediment thickness will be highly variable within the study area. In addition to this issue, outcropping carbonates are in general very hard in contrast to the materials covered by them. The top carbonate unit is formed by massive banks of grainstonepackstone limestones with sparitic cement and bioclastic wackestone carbonate (IGME, 1997). The next unit above includes two intervals. The first one is composed by marly limestones and marls on top of limestones as well as fine sediments (silts, marls, lutites). The second one is an heterogeneous interval with marls, bioclastic limestones, calcarenites, sandy limestones, sandstones and lutites with a high content of organic material. These Upper Cretaceous units lie unconformably on a Lower Cretaceous unit known as Utrillas, as described above. This unit is characterized by partially cemented siliciclastic sediments. Based on this description, a high-to-low stiffness profile (from top to bottom) is expected, which adds more complexity to the near-surface structure.

\section{Geophysical methods}

\subsection{Geophysical well logging}

Geophysical well-logging techniques have been applied to petroleum exploration over many decades (Serra and Serra, 2004). Borehole geophysics is an integrated part of the characterization of oil/gas reservoirs. It contributes not only information about lithology and structural features but also aids assessment of the petrophysical properties of a reservoir. In recent decades, borehole logging has been extended to other fields such as hydrogeology, civil engineering, mining and environmental remediation in which small-diameter boreholes are common (Paillet et al., 2004).

Several logging tools can provide different physical properties of geological strata adjacent to boreholes. In this work, we focus on sonic and natural gamma-ray logging. For more comprehensive information about logging probes the reader is referred to the literature (e.g. Ellis and Singer, 2007).

\subsection{Passive seismic (array and $\mathrm{H} / \mathrm{V}$ techniques)}

The analysis of seismic noise is a valuable tool for subsurface characterization as shown by many authors such as Aki (1957) or Okada (2003). These techniques are founded on using the energetically dominant part of seismic noise, which consists mainly of surface waves (Bonnefoy-Claudet et al., 2006). Two different types of methods exploit surface wave energy from seismic noise.

First, array techniques focus on the surface wave dispersion (frequency-dependent phase velocity) in order to obtain a shear-wave velocity profile by inversion processes. These techniques require acquisition of seismic noise simultaneously on a group of seismometers. The dispersion character of surface waves can be extracted using different methods. In this work, we focus on the frequency-wavenumber (FK) method and spatial autocorrelation (SPAC) method. 


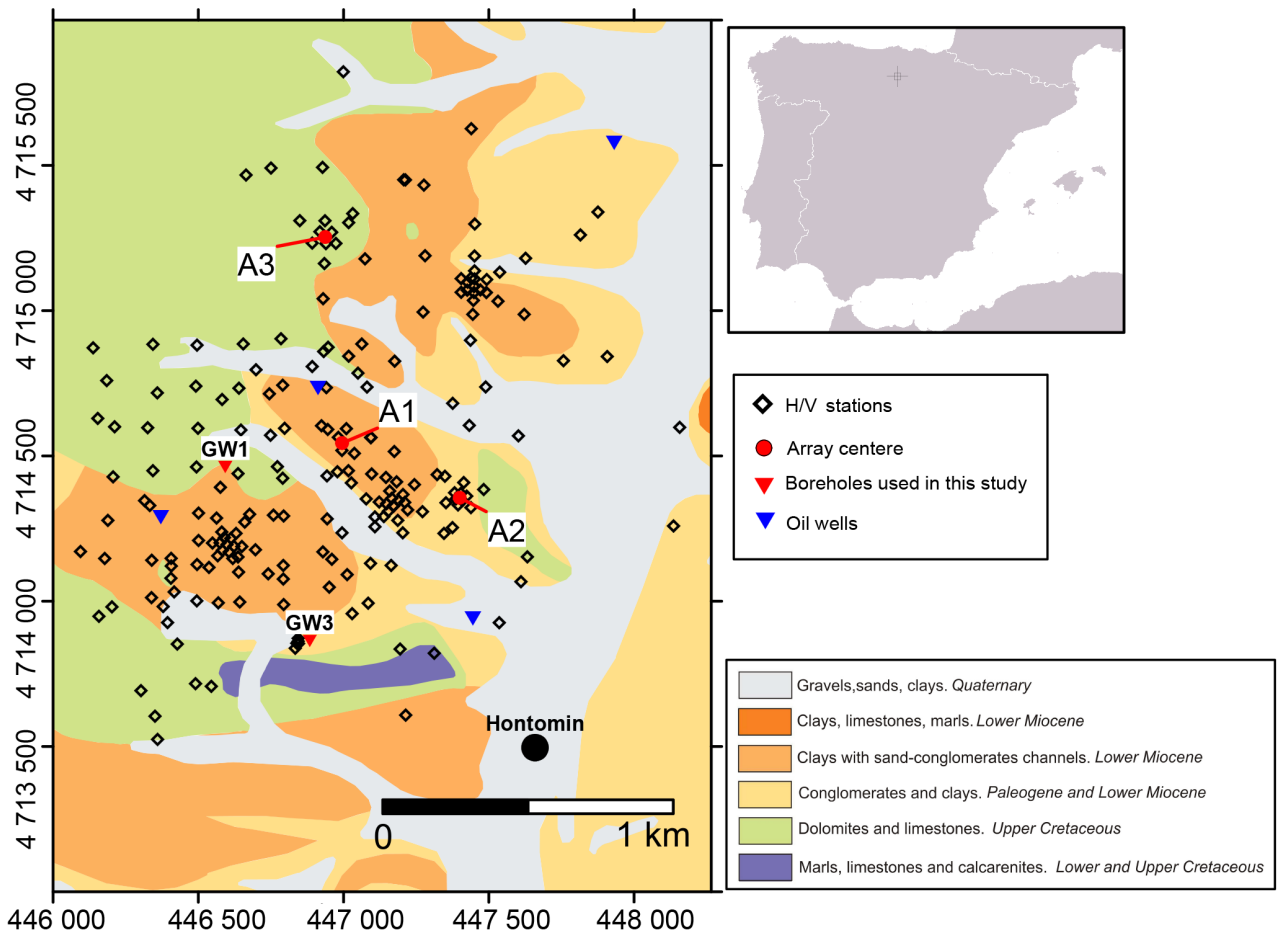

Figure 1. Surficial geological map of the study area (Quintà, 2013) with locations of the H/V measurements, the array centres and the boreholes discussed in this paper (UTM coordinates in m, ETR89 datum). Overview map of the Iberian Peninsula with location of the study area.

\subsubsection{Array data analysis with FK method (Horike, 1985)}

This method is based on the assumption that waves arrive in a plane across the receiver setup. The velocity is calculated for different frequency bands and for short time windows after cutting the signal at a specific length depending on the frequency. FK transform is performed to these cut signals. Focusing at a particular frequency, the phases of each signal are shifted, corresponding to differences in arrival times at each sensor for specific velocity and direction of plane wave propagation $\left(k_{x}, k_{y}\right)$. The stacking of the shifted signals is done in the frequency domain, providing a semblance value. Repeating this process for specific wavenumber, velocity and frequency values within a defined range, a complete beam power plot is retrieved. Maxima search methods of this plot provide an estimation of the travel velocity and direction of the waves. Figure 3 is a compilation of histograms of the pair frequency and velocity obtained from the semblance maximum search at each time window and for each frequency.

\subsubsection{Array data analysis with SPAC method (Aki, 1957)}

Another method to analyse array signals is the spatial autocorrelation method (SPAC) that assumes a random distribution of seismic sources both in space and time. Aki (1957) has shown that the autocorrelation ratios between two receivers is dependent on the phase velocity and the array geometry. The application of this method uses the mean of autocorrelation ratios $\bar{\rho}$ obtained at each pair of receivers located at a distance $r$ and considering all azimuths.

$\bar{\rho}(r, \omega)=J_{\mathrm{o}}\left(\frac{\omega r}{c(\omega)}\right)$,

where $J_{\mathrm{O}}$ is the zeroth-order Bessel function, $c(\omega)$ is the phase velocity for a certain frequency. Aki (1957) proposed circled array configuration with different radii to obtain $c(\omega)$.

Bettig et al. (2001) introduced a modification of the SPAC method that allows the method to be applied for different array configurations. With this modified SPAC method, the autocorrelation coefficients are obtained from station pairs separated by a distance $r$ within a certain range $\left(r_{1}, r_{2}\right)$ or rings instead of a fixed distance. Since this method is suitable for different configurations, the same geometry can be used to apply both FK and SPAC methods.

Dispersion or autocorrelation curves are subsequently inverted to obtain a shear-wave velocity profile. Since we are dealing with a 1-D method, this information is assigned to the centre of the array setup. 


\subsubsection{H / V technique}

In addition to the array techniques, a second way of analysing seismic noise is the horizontal-to-vertical $(\mathrm{H} / \mathrm{V})$ spectral ratio method. The $\mathrm{H} / \mathrm{V}$ method computes the ratio between the Fourier amplitude spectra of the horizontal and vertical components of seismic noise measurements at a single station. This technique is based on the idea that frequencydependent ellipticity of surface wave motion can explain the $\mathrm{H} / \mathrm{V}$ spectral ratio shape. In areas characterized by sediment over hard rock, the $\mathrm{H} / \mathrm{V}$ spectral ratio peak is associated to the soil resonance frequency (Nogoshi and Igarashi, 1970). This technique was revised by Nakamura (1989) and has been proposed as a quick, reliable and low-cost technique for site-effect characterization in earthquake seismology (Lermo and Chávez-García, 1993; Bard, 1999). Since the 1990s, several authors have introduced the $\mathrm{H} / \mathrm{V}$ method as suitable for exploration studies (e.g. Ibs-von Seht and Wohlenberg, 1999; Delgado et al., 2000; Benjumea et al., 2011). These studies benefit from the relationship between the soil resonance frequency $\left(v_{0}\right)$ and bedrock depth $(H)$ to delineate bedrock geometry on basins (Gabàs et al., 2014). A relationship between these two quantities $\left(v_{0}\right.$ and $H$ ) includes the average shearwave velocity of the sediments $\left(V_{\mathrm{s}}\right)$ :

$v_{0}=\frac{V_{\mathrm{s}}}{4 \times H}$.

\section{Data acquisition and processing}

\subsection{Geophysical well logging}

During February 2012 geophysical logs were acquired in two boreholes in the study area: GW-1 up to $400 \mathrm{~m}$ depth and GW-3 that reached $150 \mathrm{~m}$ depth (Fig. 1). Two probes were used: a dual induction with natural gamma sensor and a three-receiver sonic probe. The logging equipment is from Robertson Geologging Ltd and includes a $500 \mathrm{~m}$-winch. In this work we focus on total natural gamma-ray values and $P$ - and $S$-wave velocities obtained from the sonic data set. The sonic probe has three receivers spaced $20 \mathrm{~cm}$ to record full-waveform data generated by a monopole source. Measurements for the two sondes were made in the upward direction.

Data processing for both records includes depth matching and 11 point median filter to remove spikes. The full-wave sonic data set was processed to measure the formation compressional and shear-wave velocities. To obtain $P$-wave velocities we use a combination of manual first-arrival identification and semblance analysis (Kimball and Marzetta, 1984). The steps of this combined processing are as follows: filtering the signals for DC removal, obtaining a semblance plot with the three filtered signals, identifying the first maximum of the semblance map corresponding to the $P$-wave arrival, manually identifying the first arrival at the first receiver, ob- taining a theoretical first-arrival time for receivers two and three using the velocity calculated from semblance analysis and assuring quality control of these theoretical arrivals. In case of differences between the theoretical and experimental arrival, the first arrival of the first receiver or the maximum selection on semblance plot should be adjusted. This procedure helps to select a maximum on the semblance analysis in case of multiple maxima and also helps to identify first arrivals with low signal-to-noise ratio.

Regarding shear-wave velocity, traditional acoustic log measurements use semblance analysis to retrieve this value from the refracted shear wave. However, this is only possible in fast formations where shear-wave velocity is higher than $P$-wave velocity of the borehole fluid. If fluid velocity is higher than $S$-wave velocity, no shear-wave arrival is detected (no critical refracted wave is generated). Some authors estimate $V_{\mathrm{s}}$ from a set of geophysical logs (e.g. Singh and Kanli, 2016). In others studies, Stoneley waves analysis is used to retrieve $V_{\mathrm{s}}$ information (e.g. Stevens and Day, 1986). In the present work, the lack of low frequencies precluded the use of Stoneley waves for $V_{\mathrm{s}}$ estimation. Only some sectors of shear-wave velocity have been obtained in both boreholes corresponding to fast formations.

\subsection{Passive seismic survey}

\subsubsection{Array method}

Previous geological information obtained from lithological descriptions of oil well $\mathrm{H}_{2}$ (Alcalde et al., 2014), in addition to $P$ - and $S$-wave velocity extracted from well logging in this work, helps to define a seismic velocity model of the study area. This model has been used as input for generating a dispersion curve model.

Three 2-D arrays were deployed at the test site (Fig. 1). The procedure for each array consisted of recording simultaneous seismic noise at six stations forming two equilateral triangles with two different radii to a common centre where a seventh sensor was located. One triangle was rotated $60^{\circ}$ respect to the other one in order to obtain good azimuthal coverage (Fig. 2). After the first recording, the inner triangle was moved to a corresponding outer triangle, keeping the same centre, and a second time window was acquired. This procedure was repeated, increasing the distance from the triangle vertex to the centre. Array 1 and 3 used radii of 25, $55,100,250,400$ and $1000 \mathrm{~m}$. For array 2, the radii were $10,25,55,100,400$ and $750 \mathrm{~m}$. The minimum radius for this array is smaller than for arrays 1 and 3 , since a significant thickness for unconsolidated sediments was expected. Seven Sara SL06 digitizers were connected to seven triaxial Lennartz LE-3-D/5 s sensors. The sensors were covered by a plastic box to reduce wind noise. The sampling rate was fixed to 200 samples s $^{-1}$. All stations were equipped with GPS timing. 


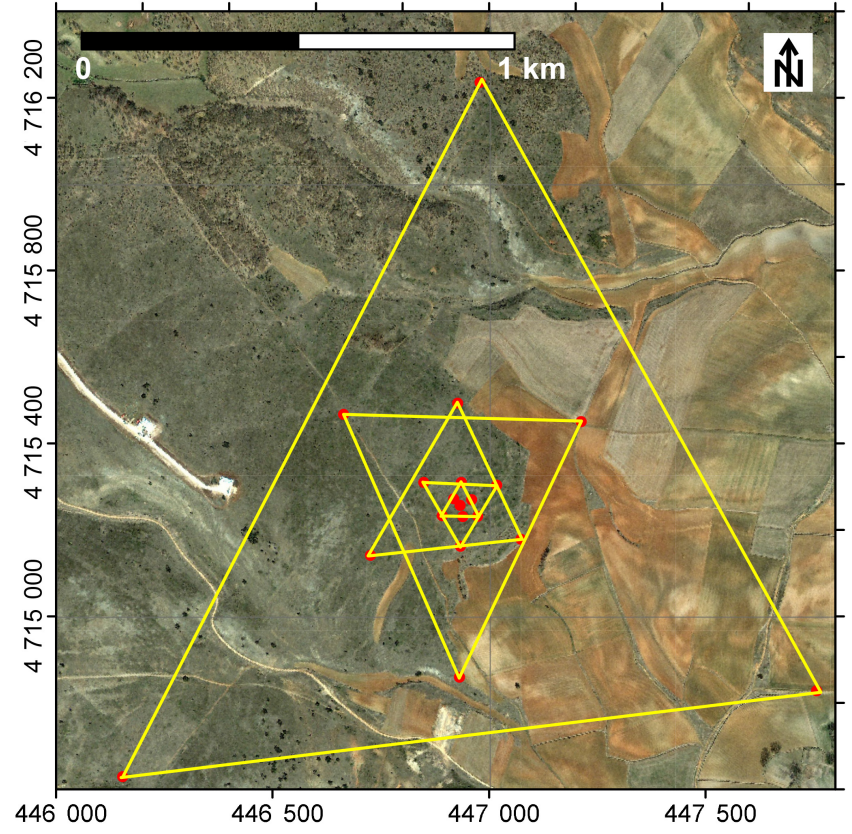

Figure 2. Geometry used for the seismic noise measurements at array 1 . Red circles mark the position of the stations and yellow lines show the triangle setup. Map is shown in UTM coordinates in $\mathrm{m}$, ETRS89 datum.

To constitute our input data set for retrieving shear-wave velocity, we can either use measured dispersion curves for FK method or extract autocorrelation curves using the SPAC method. Both techniques have been tested and yield similar results. Data processing has been carried out using Geopsy (http://geopsy.org/).

Figure 3 shows an example of FK histograms for each triangle combination corresponding to array 1-MT 12. Dotted and continuous black lines mark the limits for resolution and aliasing obtained from maximum wavenumber and minimum wavenumber respectively. These limits are calculated from the array response for the applied geometry (Wathelet et al., 2008). Continuous black lines with error bars mark the maximum of the histogram related to the dispersion of surface waves energy of seismic noise. The combined dispersion curve corresponding to all the radii is shown in Fig. 4. Slowness slightly decreases with frequency for frequencies higher than approximately $4 \mathrm{~Hz}$. This relationship indicates the presence of high-velocity layers overlying lower-velocity material.

Regarding SPAC processing, we have used the modification proposed by Bettig et al. (2001), calculating the spatial autocorrelation curves on four rings of different radius ranges. An example of these curves for array 1 is shown in Fig. 5.

A unique dispersion curve (DC) built from the DC of each configuration has been inverted using the neighbourhood algorithm that carries out an stochastic search through the model space ( $P$-wave velocity, $S$-wave velocity, density and thickness layer). The algorithm was adapted and implemented by Wathalet (2008) in the Dinver software. The same software has been used for the inversion of the autocorrelation curves obtained from the SPAC method.

We have tested different parameterizations including $n$ uniform layers over the half-space (n varies from 1 to 6 ). The velocity and thickness for each layer are constrained by certain ranges. Knowing the presence of velocity inversion helps parameterization for both DC and SPAC curves inversion. We also define a coupling between $P$ and $S$ waves for each layer. The obtained dispersion and autocorrelation curves are inverted with the neighbourhood algorithm generating a total of 12550 models for each technique and parameterization test. The final models have been chosen for a specific number of layers that provides optimum misfit and the simplest models. Only the models with a misfit less than 0.9 will be considered. The misfit function is defined according to Wathelet et al. (2008).

\subsection{2 $\mathrm{H} / \mathrm{V}$ method}

$\mathrm{H} / \mathrm{V}$ data acquisition has been carried out in two different field surveys: one in 2010 and the second one in 2013 with a total of 224 stations. For the first survey, a total of 150 single station measurements have been used. The stations were formed by a Spider digitize system (Worldsensing) and a $5 \mathrm{~s}$ three-component Lennartz (LE-3D $5 \mathrm{~s}$ ). Sampling frequency was $100 \mathrm{~Hz}$ and record length varied from 15 to $60 \mathrm{~min}$ depending on location. For the second survey, 17 new H / V measurements in addition to 57 data sets coming from array stations have been analysed. In this case, the station included a SARA SL06 digitizer and the same seismometer as the first survey. Sampling frequency was set up to $200 \mathrm{~Hz}$ and record length ranged between 20 and $120 \mathrm{~min}$.

$\mathrm{H} / \mathrm{V}$ spectral ratios were computed by dividing the noise recordings into 120 to $300 \mathrm{~s}-$ long windows. The resulting $224 \mathrm{H} / \mathrm{V}$ spectral ratios were analysed considering the recommendations proposed by SESAME (Bard et al., 2004).

\section{Results and interpretation}

\subsection{Geophysical logging and seismic velocities}

Figure 6 shows the $P$ - and $S$-wave logs of the GW-1 and GW-3 boreholes obtained from the processing of the three receiver full-waveform records. The records corresponding to the far receiver and the gamma-ray log are also included. $P$-wave-velocity $\log \left(V_{\mathrm{p}}\right)$ shows significant variation in the GW-3 borehole and up to $200 \mathrm{~m}$ depth in the GW-1 borehole. At the shallow part, velocity log is characterized by a high-velocity layer overlying a zone with a significant velocity decrease with depth. The bottom of this high-velocity layer is $37 \mathrm{~m}$ deep in the GW-1 borehole and $62 \mathrm{~m}$ deep in the GW-3 borehole. Below this zone, a high-velocity thin layer 

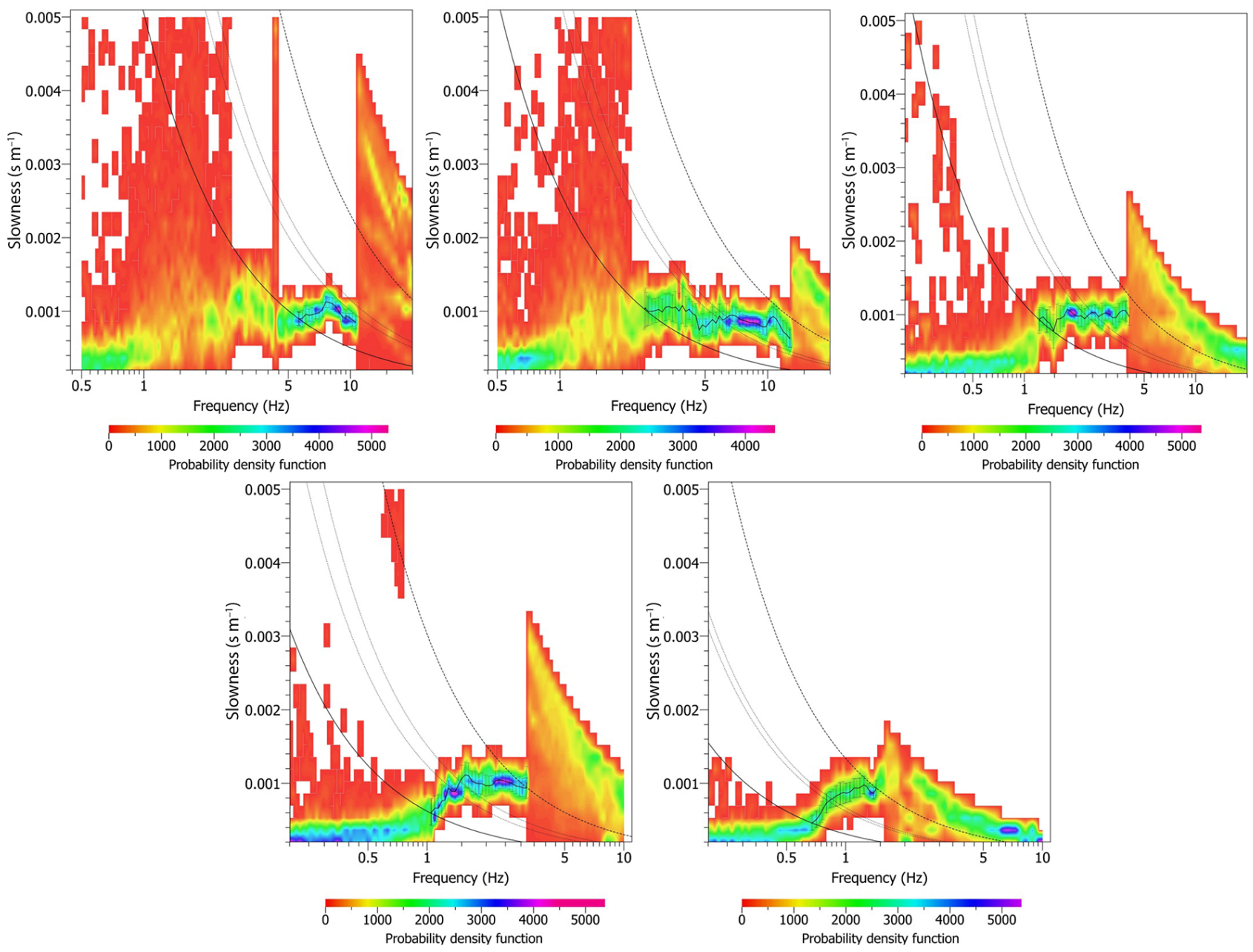

Figure 3. Histograms of velocities obtained from frequency-wavenumber analysis for each triangle configuration performed for array 1 . For each plot the black line with error bars mark the dispersion curve. The continuous line indicates a constant wavenumber value of $k_{\text {min }} / 2$ related to the resolution limit of this array geometry (Wathelet et al., 2008). The dashed line is a constant wavenumber value of $k_{\max }$ that defines the aliasing limit constrained by the array geometry. The dots represent $k_{\min }$ (left) and $k_{\max } / 2$ (right).

can be observed at $86 \mathrm{~m}$ depth at the GW-1 location and at $110 \mathrm{~m}$ depth in the GW-3 borehole. This sharp $V_{\mathrm{p}}$ change can be used as stratigraphic marker. From $92 \mathrm{~m}$ depth down to $200 \mathrm{~m}$ depth, the $P$-wave-velocity $\log$ of the GW-1 borehole shows a pattern of alternating maximum-minimum velocity values. The last sector (below $200 \mathrm{~m}$ ) at the GW-1 borehole is quite uniform with velocity values within a range of 3200$3600 \mathrm{~m} \mathrm{~s}^{-1}$. The gamma-ray response shows very low values $(<15 \mathrm{cps})$ in the shallow part up to $37 \mathrm{~m}$ depth of the GW-1 borehole and up to $62 \mathrm{~m}$ depth of the GW-3 borehole. This is in agreement with the high-velocity layer delineated by the sonic $\log$. Below this layer, the gamma-ray response smoothly increases down to a depth of $82(\mathrm{GW}-1)$ and $100 \mathrm{~m}$ (GW-3). The natural gamma readings of the GW-1 borehole follow an alternating pattern of maximum and minimum values from that depth down to the borehole bottom. The maximum values are located in the sector below $200 \mathrm{~m}$ depth.
A detailed lithological interpretation of both types of sequences is conducted based on the geophysical properties. Since boreholes drilled two different geological environments: marine (Upper Cretaceous) and continental (Lower Cretaceous), different logging data sets have been used for a detailed interpretation of each borehole.

On the one hand, Upper Cretaceous materials are mainly limestone rocks where porosity, pore types and insoluble content control the variation of physical parameters (Eberli et al., 2003). Regarding elastic properties, there is not a direct correlation between seismic velocities and depth of burial or age. Velocity inversions with increasing depth are common such the observed ones in Fig. 6. Seismic properties combined with gamma-ray measurements will be used in order to characterize Upper Cretaceous rocks following the next steps: 


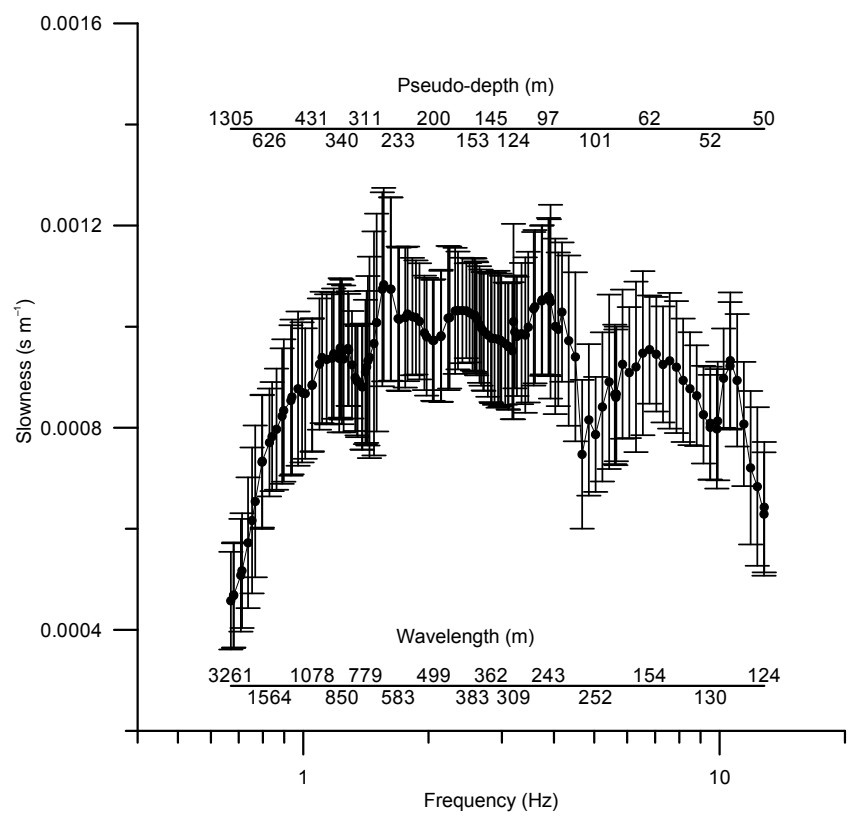

Figure 4. Total dispersion curve for array 1 obtained from the combination of the dispersion curves shown in Fig. 3. The corresponding wavelength for each slowness and frequency values is indicated in a bottom auxiliary axis as well as the pseudo-depth (top auxiliary axis) calculated as wavelength/2.5.

- Zonation process based on two physical parameters $\left(V_{\mathrm{p}}\right.$ and natural gamma). This process was made using WellCad software and identifies depth intervals with similar characteristics (Davis, 2002).

- Mean value calculation at each interval and for each parameter.

- Crossplots of the mean values and visual cluster recognition. $V_{\mathrm{p}}$ and natural gamma coming from GW-1 and GW-3 are merged together in a single plot (Fig. 7a). The criterion for clustering has been identifying lowest gamma values and highest $P$-wave velocity values. The grey ellipsoid in Fig. 7a delineates this cluster interpreted as pure or massive limestone. Fast velocities $\left(>4000 \mathrm{~m} \mathrm{~s}^{-1}\right.$ ) are reached if the clay content is below $5 \%$ (Eberli et al., 2003). The rest of the points are related to marly limestones and marls.

- Projection of these two clusters to the corresponding depth interval in the well-log plot (pure limestones in blue, and marly limestones and marls in purple).

On the other hand, lower Cretaceous sediments are characterized by alternating gravel/sand and claystones. Hence, seismic velocity changes are not suitable for distinguishing between layers since velocity ranges overlap for these lithological types. This fact has been confirmed by the uniformity of $P$-wave velocity values within this sector (Fig. 6).
However, natural gamma logs can help to discriminate between gravels/sands and clays (Fig. 7b). Having established three ranges of gamma values based on the histogram, the projection to the depth column of these groups has been made (Fig. 6). The ranges of gamma values have been established as 30-55 cps for gravels/sands (yellow), $55-85 \mathrm{cps}$ for clay/gravel mix (orange) and 90-120 cps for clays (red).

Using the lithological description of both boreholes and based on the aforementioned geophysical parameters, we have delineated the passage from the Upper Cretaceous materials rock to the Lower Cretaceous sediments at $180 \mathrm{~m}$ depth at the GW-1 location.

\subsection{Passive seismic}

\subsubsection{Array-shear wave velocity}

Figure 8 shows the results $\left(V_{\mathrm{s}}\right)$ from dispersion (FK) and autocorrelation (SPAC) curves inversion corresponding to each array. This figure allows comparison of both technique capabilities for shear-wave velocity characterization and contact delineation. Both models show a similar structure. The main characteristics are given below:

(i) The first layer shows low velocity at array 1 (around $\left.500 \mathrm{~m} \mathrm{~s}^{-1}\right)$ and array $2\left(150-290 \mathrm{~m} \mathrm{~s}^{-1}\right)$. For array 3, this layer is characterized by higher velocity (660$820 \mathrm{~m} \mathrm{~s}^{-1}$ ). The thickness varies from 7 to $20 \mathrm{~m}$ at array 2 to $25 \mathrm{~m}$ at arrays 1 and 3 .

(ii) The second layer displays high velocity (1400$2000 \mathrm{~m} \mathrm{~s}^{-1}$ ) for the three arrays. This layer bottoms at 55-60 (array 1), 65-70 (array 2) and $85 \mathrm{~m}$ (array 3).

(iii) The third layer shows the main differences between the FK and SPAC solutions for array 1. The inversion of autocorrelation curves requires the incorporation of two sublayers to assure a good fit. The first one reaches $315 \mathrm{~m}$ depth with $870 \mathrm{~m} \mathrm{~s}^{-1}$ shear-wave velocity, whilst the second one of $1300 \mathrm{~m} \mathrm{~s}^{-1}$ shows a maximum bottom depth of $765 \mathrm{~m}$. The FK velocity model shows a velocity of $1100 \mathrm{~m} \mathrm{~s}^{-1}$ and a bottom depth of $700 \mathrm{~m}$ for this third layer at array 1 . On the other hand, shear-wave velocity is 1050 (array 2) and $1100 \mathrm{~m} \mathrm{~s}^{-1}$ for array 2 and 3 respectively. This layer reaches $570 \mathrm{~m}$ (from SPAC) or $630 \mathrm{~m}$ (from FK) at array 2, whereas it shows a maximum bottom depth of $730 \mathrm{~m}$ at array 3 .

(iv) The shear-wave velocity of the last layer shows different values depending on the applied array technique. It ranges from 2300 to $3000 \mathrm{~m} \mathrm{~s}^{-1}$. The decrease of resolution of the method makes the uncertainty of shearwave velocity higher at this depth. However, we can expect fast formation at depths higher than $600-700 \mathrm{~m}$.

Velocity inversion stands out from these models, in particular between layer 2 and layer 3 . 

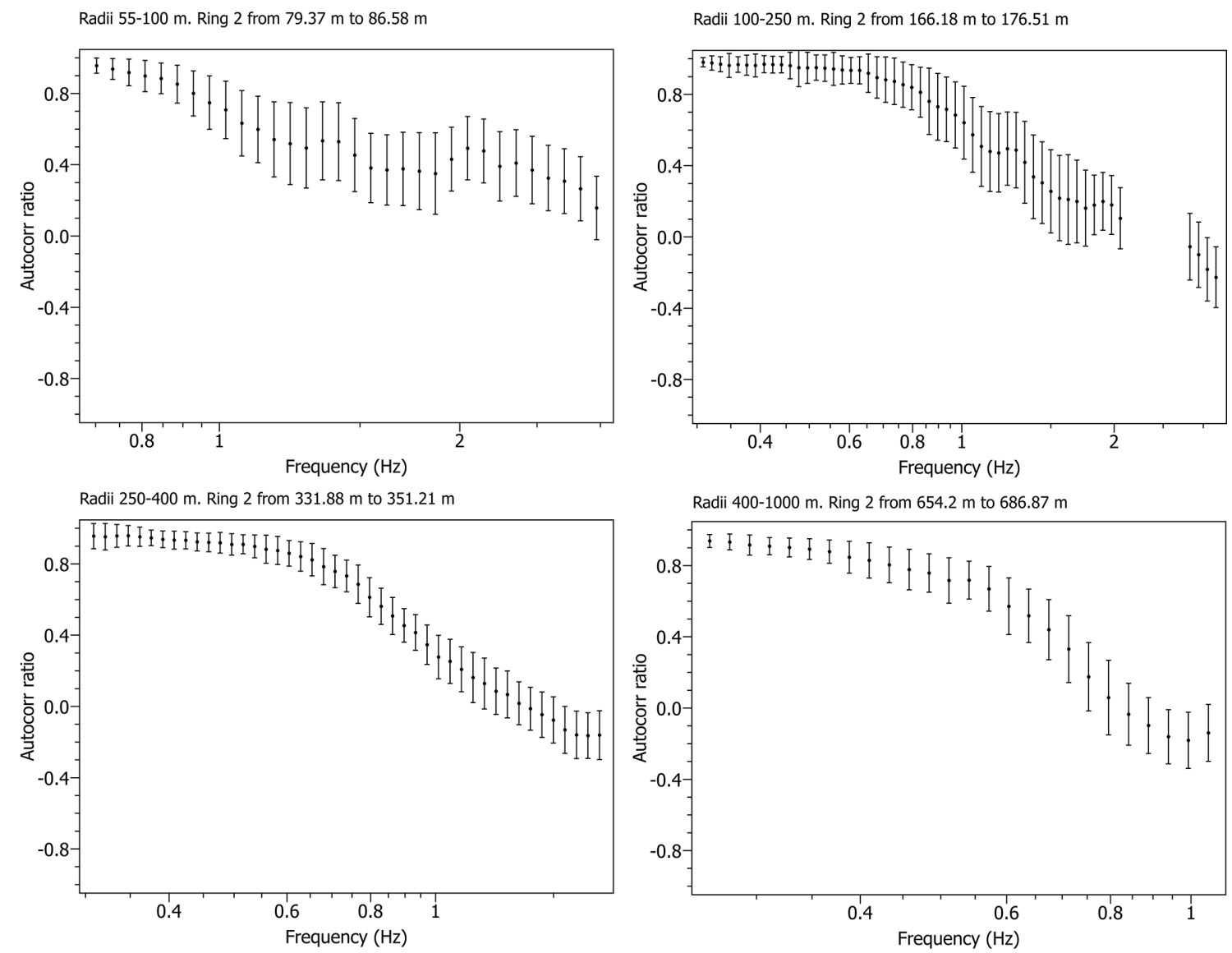

Figure 5. SPAC analysis. Autocorrelation curves (grey dots with error bars) obtained for array 1 at each ring.

The first layer could be interpreted as Quaternary/Tertiary sediments. The second one could be related to the Upper Cretaceous lying over the third one, interpreted as Utrillas and probably topmost Escucha sediments. Finally the last layer can be interpreted as the bottom of the Escucha Formation or Wealden with Purbeck facies. The shallow part of the velocity model including the velocity inversion will be compared with the logging results in the Discussion section.

\subsection{2 $\mathrm{H} / \mathrm{V}$ frequencies and sediment thickness map}

We have obtained the $\mathrm{H} / \mathrm{V}$ spectral ratio for the 224 stations. The shape of these ratios can be classified in four different types.

(i) $\mathrm{H} / \mathrm{V}$ spectral ratios show clear peaks that can be related to the soil resonance frequency at that station (Fig. 9a).

(ii) Multiple peaks can be identified. This H / V morphology is associated to multiple impedance contrasts and/or 2-D/3-D bedrock structure. In both cases, it is difficult to assign a soil resonance frequency although adjacent stations or other geophysical results can help to define that frequency (Fig. 9b). (iii) Flat $\mathrm{H} / \mathrm{V}$ spectral ratio indicates that the station is located on bedrock (Fig. 9c).

(iv) $\mathrm{H} / \mathrm{V}$ spectral ratio is characterized by a constant amplification over a wide frequency range, mainly at the highfrequency range $(>1 \mathrm{~Hz})$, forming a step pattern. This constant amplification is not related to subsoil structure but probably to anthropogenic seismic noise rather than to soil response (Fig. 9d). For this reason, we do not use the results corresponding to this type of $\mathrm{H} / \mathrm{V}$ shape.

$\mathrm{H} / \mathrm{V}$ frequency at each station corresponds to the frequency at the $\mathrm{H} / \mathrm{V}$ spectral ratio maximum. Figure 10 shows the frequency values colour coded on a map view from group (i). It also includes the location of the sites identified as rock sites (flat $\mathrm{H} / \mathrm{V}$ spectral ratio group (ii)) and the sites corresponding to an $\mathrm{H} / \mathrm{V}$ step pattern.

We distinguish three zones with clear $\mathrm{H} / \mathrm{V}$ peaks: two sectors in the NE and SE quadrants with fundamental frequencies ranging between 2 and $8 \mathrm{~Hz}$ and a third sector in the southern part with frequency values between 4 and $10 \mathrm{~Hz}$. In all the sectors, the fundamental frequency gradually decreases with distance to the zone centre. These sectors are related to soft soils with a significant thickness and impedance 


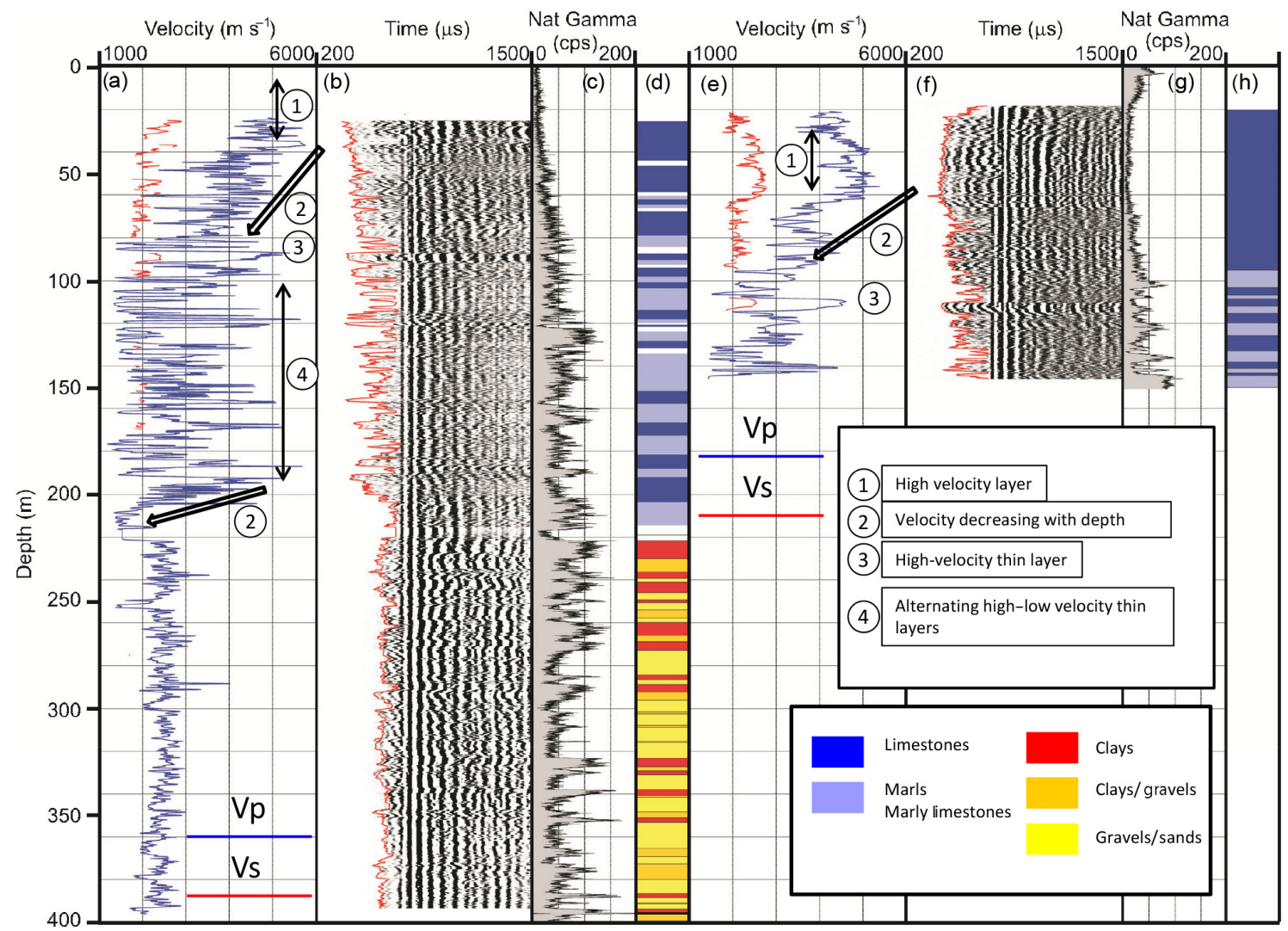

Figure 6. Panel (a) shows $P$-wave velocity (blue line) and $S$-wave velocity (red line) for GW-1, (b) shows the recorded sonic waveform for the far-receiver from the GW-1 borehole, (c) shows the natural gamma log from GW-1 and lithological interpretation resulting from zonation process and clustering as shown in Fig. 7 for GW-1. Panels (e), (f), (g) and (h) correspond to (a), (b), (c) and (d), but for GW-3.
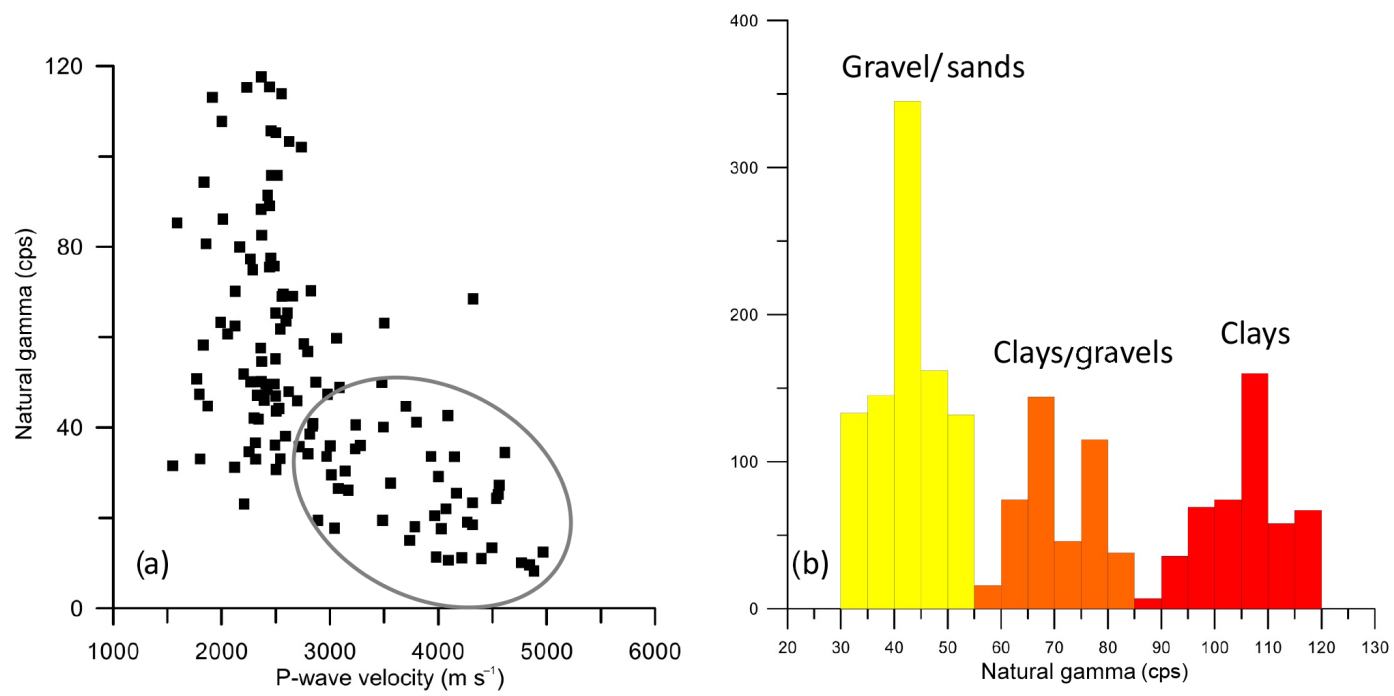

Figure 7. Panel (a) shows the crossplot of the average $P$-wave velocity and natural gamma values for each zone defined with the zonation process. The plot includes measurements from both GW-1 and GW-3 corresponding to the Upper Cretaceous sector. The grey ellipsoid encircles the points characterized by high $P$-wave and low natural gamma values interpreted as limestone. The points outside this area have been related to marly limestones and marls. Panel (b) shows the distribution of natural gamma values for Lower Cretaceous materials from GW-1 with the geological interpretation of the three histogram groups. 
(a)
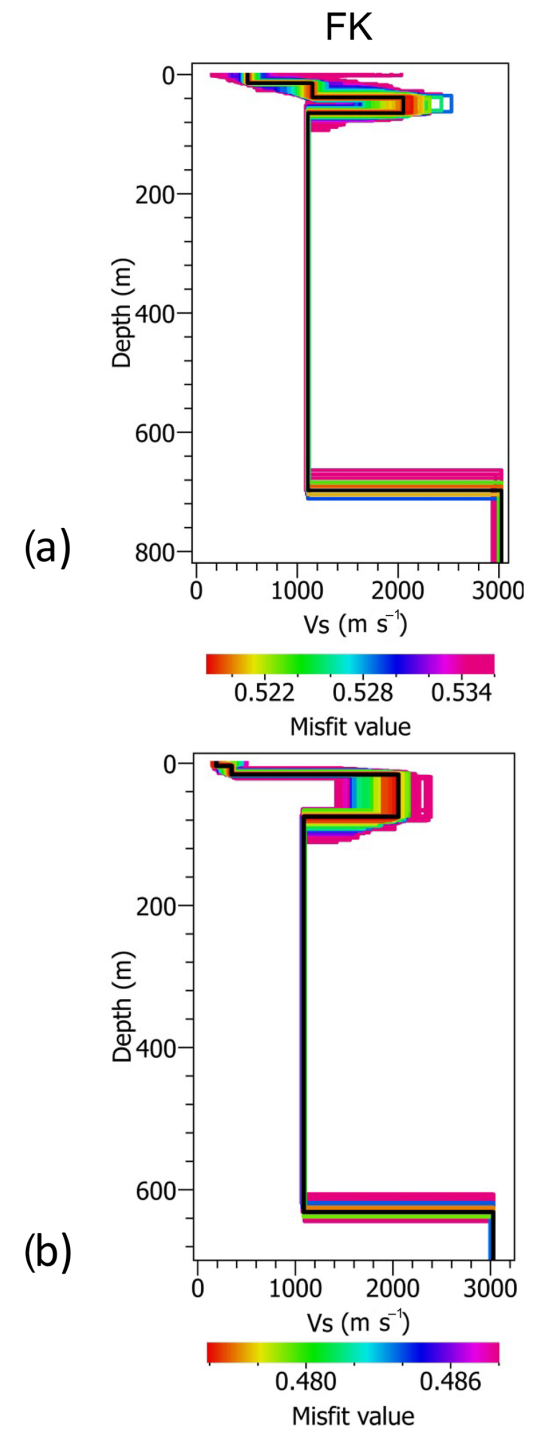

(c)

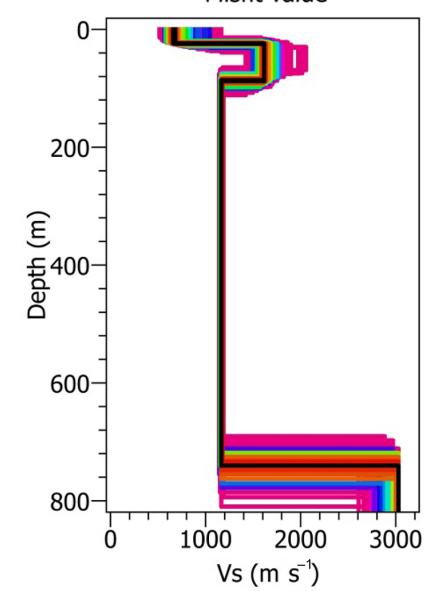

$\begin{array}{lll}0.880 & 0.884 & 0.888\end{array}$

Misfit value
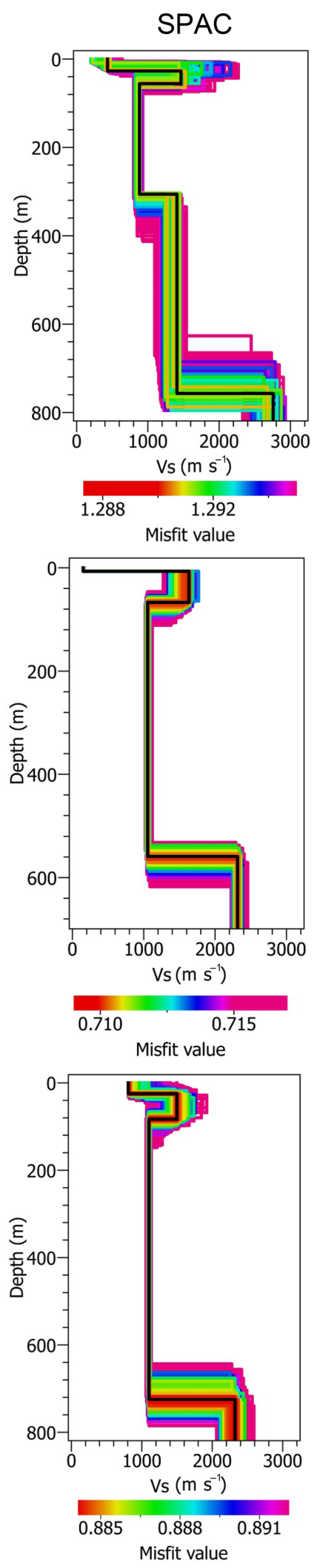

Array 2

Array 1

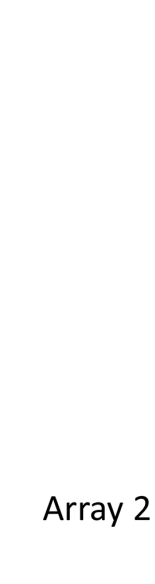

Array 3

Figure 8. Shear-wave velocity models obtained from the dispersion curve inversion (FK method, left) and the autocorrelation curves inversion (SPAC method, right) array technique for (a) array 1, (b) array 2 and (c) array 3. The models have a misfit lower than 0.9. Colour code shows the misfit of each model. The black line represents the shear-wave velocity model with minimum misfit. 

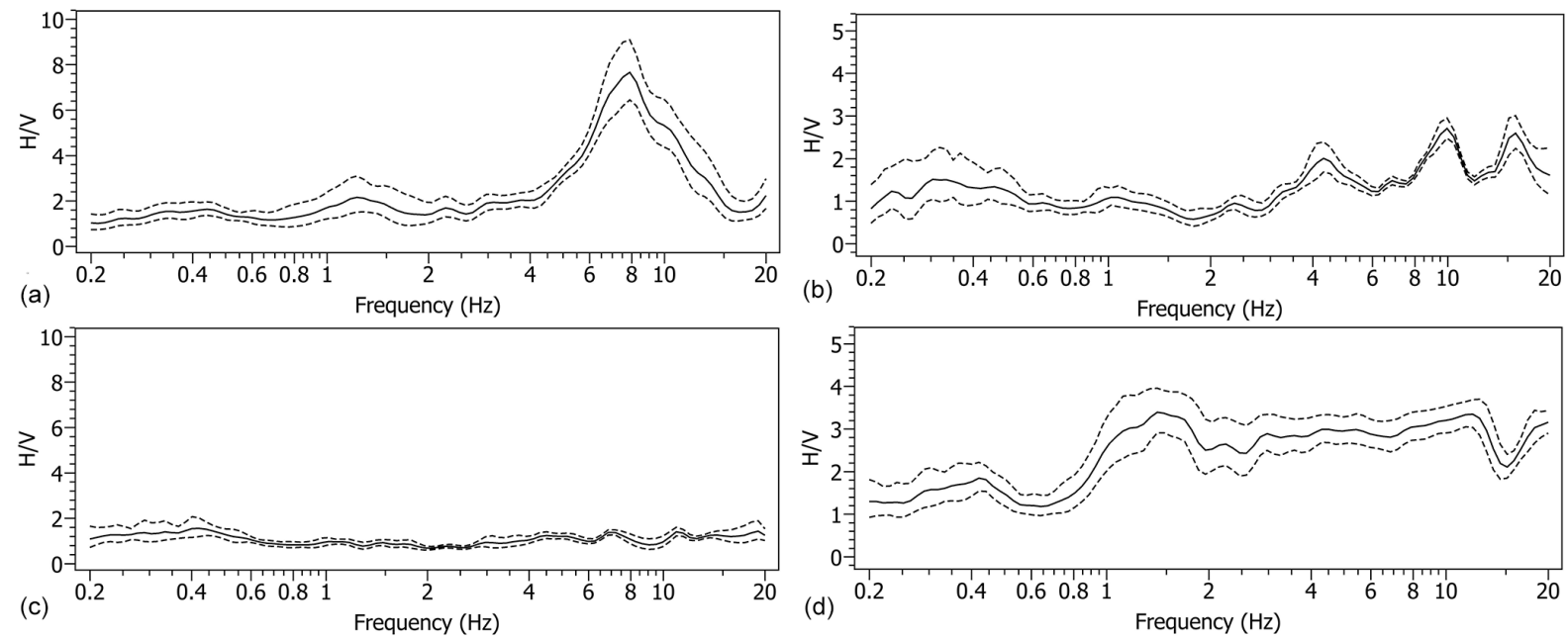

Figure 9. H / V topologies observed in the study area: (a) station with a clear peak, (b) station with multiple significant peaks, (c) station without peak and (d) H / V ratio showing constant amplification over a wide frequency range (step shape).

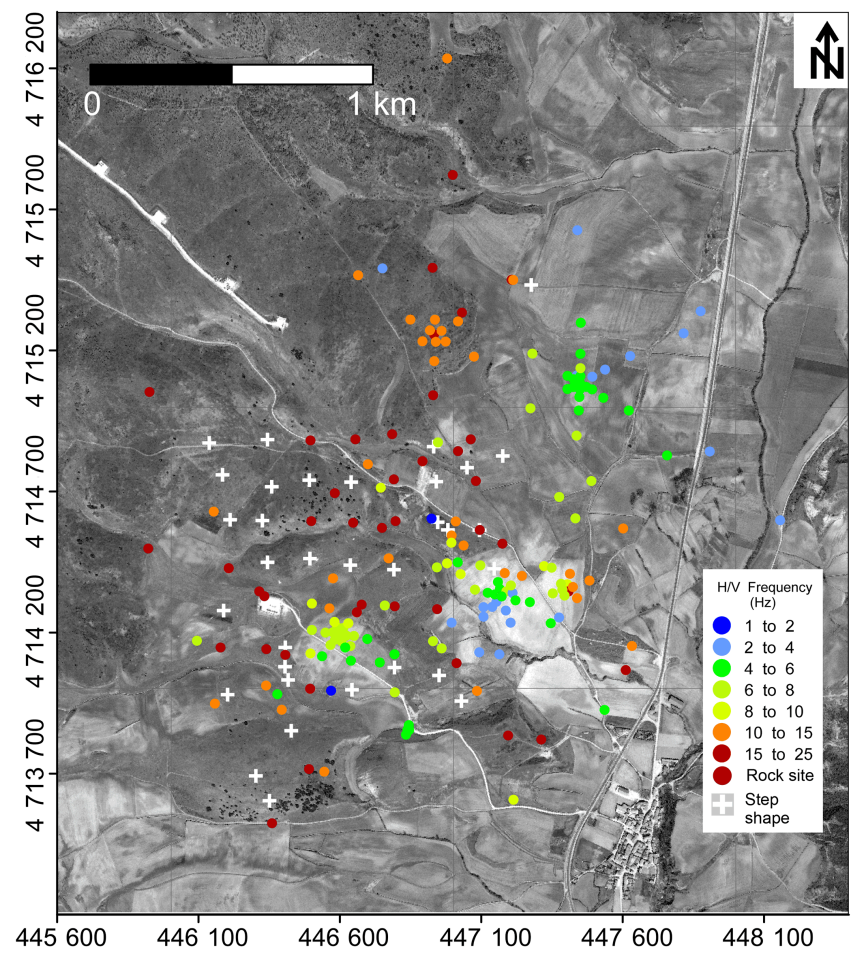

Figure 10. H / V method. Fundamental H / V peak frequencies over the study area (colour coded). White crosses denote stations with step morphology (Fig. 9). Map is shown in UTM coordinates in m, ETRS89 datum.

contrast with bedrock. Shallow bedrock or rock outcrops are located in the NW quadrant, SE end and central part of the study area.

In this study, logs of the GW-3 borehole have been used to ground truth for $\mathrm{H} / \mathrm{V}$ peak interpretation, i.e. to find which lithology can cause this fundamental frequency in the study area. One $\mathrm{H} / \mathrm{V}$ station was located next to GW-3 which showed a fundamental frequency of $4.3 \mathrm{~Hz}$. According to the GW-3 lithological interpretation, a first layer of $20 \mathrm{~m}$ thickness is composed of Quaternary and Miocene sediments (clays and silts) overlying Upper Cretaceous limestone. This contact causes a significant impedance contrast that produces the observed fundamental frequency of the soil. On the other hand, we can use this value to estimate a shear-wave velocity for the unconsolidated sediments that helps to produce sediment thickness maps. Using equation (1), a shear-wave velocity value of $344 \mathrm{~m} \mathrm{~s}^{-1}$ is obtained. As presented in the array results, the $V_{\mathrm{S}}$ range of unconsolidated sediments is 290 $500 \mathrm{~m} \mathrm{~s}^{-1}$. The value obtained at GW-3 applying $\mathrm{H} / \mathrm{V}$ technique is included within this range. Hence, $V_{\mathrm{s}}$ varies along the study area as expected from the presence of Quaternary and Tertiary sediments of different lithology. We have used the limits of the $V_{\mathrm{s}}$ range from arrays measurements to estimate a range for sediment thickness (Fig. 11). For the production of this map, the natural-neighbour gridding method has been used. This method is suitable for data sets with high density in some areas and paucity in others. Maximum thickness of the layer with $500 \mathrm{~m} \mathrm{~s}^{-1}$ shear-wave velocity varies between 40 and $45 \mathrm{~m}$ (Fig. 11a) and the layer with $290 \mathrm{~m} \mathrm{~s}^{-1}$ varies between 20 and $25 \mathrm{~m}$ (Fig. 11b).

\section{Discussion}

One of the limitations of vintage well-logging data is the dead zone in the sonic logs corresponding to the near surface. In the study area, three oil exploration boreholes lack the first $400 \mathrm{~m}$ of sonic data (Alcalde et al., 2014). In this framework, slim hole well logging is key to obtaining information about the shallow part. Both $V_{\mathrm{p}}$ and $V_{\mathrm{s}}$ have been calculated for the 

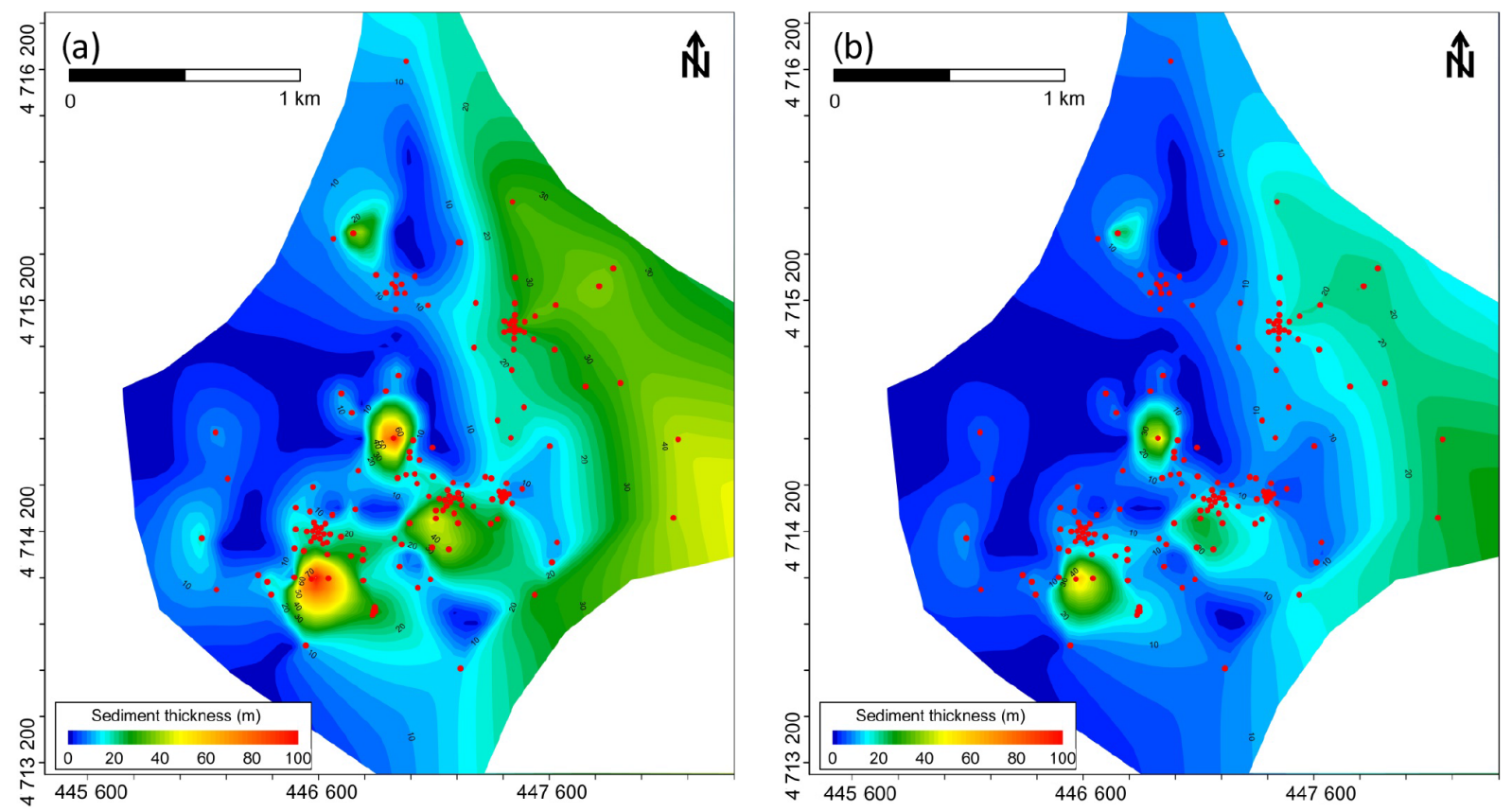

Figure 11. Contour map showing the sediment thickness obtained from interpolation of thickness values obtained from $\mathrm{H} / \mathrm{V}$ frequencies (Fig. 10) using (a) $V_{\mathrm{s}}=500$ and (b) $290 \mathrm{~m} \mathrm{~s}^{-1}$. Map is shown in UTM coordinates in m, ETRS89 datum.

shallow Upper Cretaceous limestone (first $90 \mathrm{~m}$ depth) and a complete $P$-wave-velocity log is retrieved from the sonic log for the first $400 \mathrm{~m}$. The velocity information increases our understanding of the physical properties of the Upper Cretaceous materials and Utrillas (Lower Cretaceous) rocks. It will also help to interpret the velocity information obtained with the array technique. On the other hand, the combination with gamma-ray logs has enabled us to refine the geological interpretation of this shallow part. This interpretation constrained the results for the other geophysical results obtained in this study.

Regarding the passive seismic methods, the $\mathrm{H} / \mathrm{V}$ technique can provide a detailed sediment thickness map also required for resolving near-surface issues. When borehole information is sparse, the $\mathrm{H} / \mathrm{V}$ technique can be a good alternative for obtaining bedrock-depth information that can help for statics calculation or field-survey planning. In order to decrease the uncertainty of shear-wave velocity of the unconsolidated sediments, an active surface wave survey is required. However, this study shows the potential of the passive seismic techniques to obtain bedrock depth in a fast and effective way.

The array technique results helped identification of a significant velocity inversion in the first $100 \mathrm{~m}$ depth. The bottom of the high-velocity layer has been identified between approximately 60 and $80 \mathrm{~m}$, depending on the array location and method of surface wave analysis (FK or SPAC). If we compare these results with the shear-wave velocity log obtained at GW-1 and GW-3 (Fig. 12), we observe that the bottom of the high-velocity layer would correspond to the change from a sector characterized by velocity decrease with depth to another one made by interbedded layers of high and low velocity. The influence of this type of layering in a seismic signal with a wavelength longer than the finescale details of velocity variations has been studied by numerous authors (e.g. Stovas and Ursin, 2007). According to Hovem (1995), for a large ratio between wavelength $(\lambda)$ and thickness $(d)$ of one cycle in the layering, the layered sector behaves as a homogeneous, effective medium (Backus, 1962). For low ratio, the alternate layers may be replaced by a thicker single layer using a time-average or ray velocity for the total depth range.

In our case, the seismic wavelength of the surface waves analysed with the array technique varies from 125 at $50 \mathrm{~m}$ to 500 at $200 \mathrm{~m}$ according to the dispersion curve (Fig. 4). On the other hand, spatial Fourier analysis of the GW-1 sonic $\log$ from 92 to $200 \mathrm{~m}$ gives two maximums at 10 and $18 \mathrm{~m}$. In our case, the $\lambda / d$ ratio would range between 5 at $92 \mathrm{~m}$ and 25 at $200 \mathrm{~m}$. Since these values would correspond to different models (Backus average or time-average velocity), we have considered both models.

Firstly, a $P$-wave time-average velocity has been obtained from 92 to $200 \mathrm{~m}$ giving a value of $2348 \mathrm{~m} \mathrm{~s}^{-1}$. This is in agreement with a velocity inversion between the near-surface limestone and the layers below (marly limestones and marls). Since $S$-wave velocity is not available for this sector we cannot obtain an $S$-wave time-average velocity. 


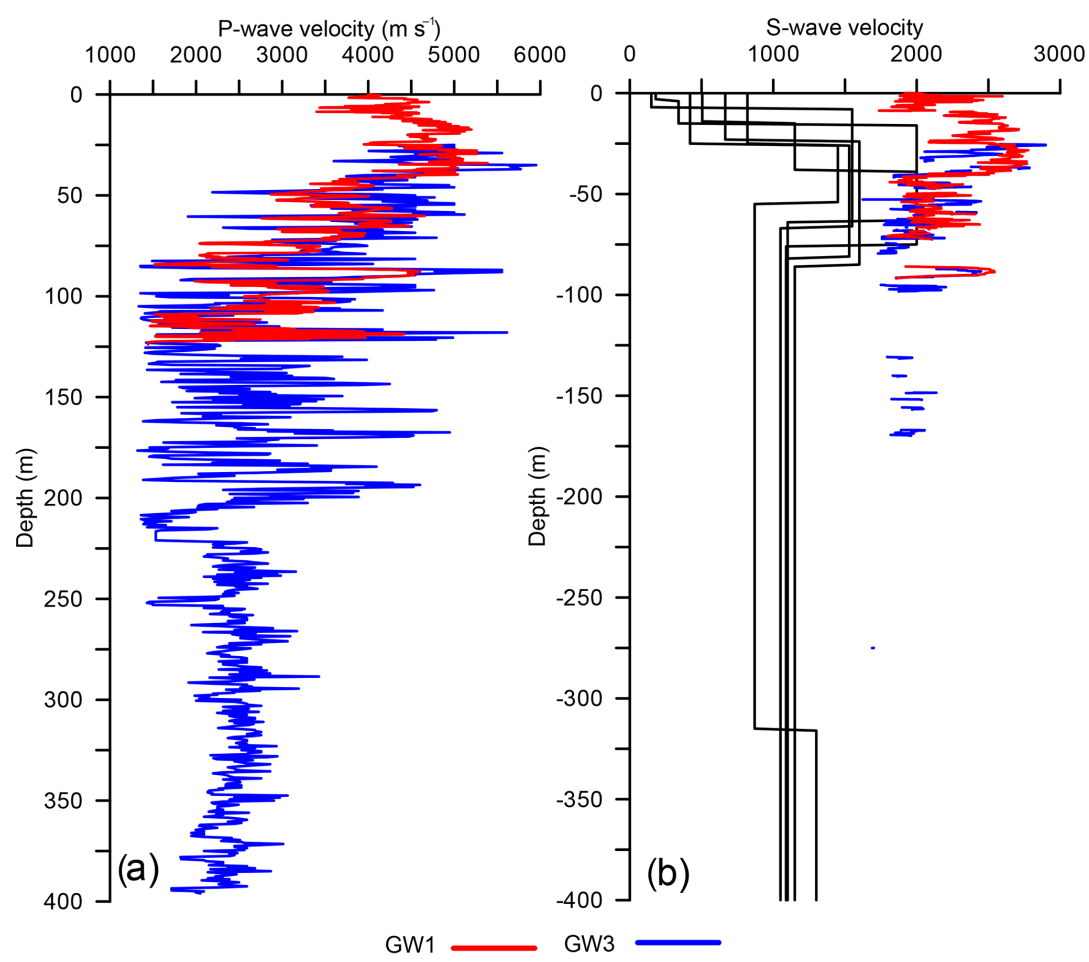

Figure 12. (a) $P$-wave velocity logging for GW-1 borehole (blue line) and GW-3 (red line). (b) $S$-wave velocity logging for GW-1 borehole (blue line) and GW-3 (red line). Shear-wave velocity obtained from the array technique (black lines).

Secondly, from a Backus average point of view, we need first to define the number of layers and assign a $P$ - and $S$-wave velocity characteristic of the high and low-velocity layers. For a characteristic thickness of $10 \mathrm{~m}$, we can use a number of 10 layers with alternating high and low velocity as equivalent to the interbedded layer sector ( 92 to $200 \mathrm{~m}$ ). The $P$ wave for the high -velocity layers has been fixed to $4000 \mathrm{~m} \mathrm{~s}^{-1}$ and for the low-velocity layers to $1500 \mathrm{~m} \mathrm{~s}^{-1}$. This leads to a Backus $P$-wave velocity of $1986 \mathrm{~m} \mathrm{~s}^{-1}$. Regarding $S$-wave velocity, we have chosen a high velocity of $2000 \mathrm{~m} \mathrm{~s}^{-1}$, confirmed by $V_{\mathrm{s}}$ calculation from sonic $\log$ where some hints of shear-wave velocity were obtained at the high-velocity layers (e.g. at around $150 \mathrm{~m}$ depth of GW$1)$. For the low-velocity layers, we have used the Poisson's ratio value (0.31) obtained by Dvorkin et al. (2001) from rock physics analysis of well-log data in marls. This value corresponds to a $V_{\mathrm{p}} / V_{\mathrm{s}}$ ratio of 1.91 , hence leading to a shear-wave velocity of $790 \mathrm{~m} \mathrm{~s}^{-1}$. Using the Backus average equation for shear-wave velocity, we obtain a velocity of $1040 \mathrm{~m} \mathrm{~s}^{-1}$. This equivalent layer velocity is similar to the one obtained from the array technique and would explained the observed velocity inversion.

However, the transition from Upper Cretaceous to Lower Cretaceous materials has not been resolved by the array technique. The time-average or the Backus average for the $P$ wave velocity is of the same order than the one obtained for the Low Cretaceous rocks (average velocity of $2300 \mathrm{~m} \mathrm{~s}^{-1}$ ).
Hence the effective medium corresponding to the interbedded sector is indistinguishable of the Utrillas sediments from a seismic array point of view. $P$-wave-velocity log enables the detection of this change associated with the Upper to Lower Cretaceous transition.

When we compare the $S$-wave velocity values obtained from well logging and the array technique, we observe that array velocity is always lower than $S$-wave logging velocity. This result is consistent with the fact that sonic logging uses high-frequency signals which travel at a different velocity than low-frequency seismic signals (Box and Lowrey, 2003). Due to the dispersion effects, the pulses generated with a sonic probe travel a few percent faster than the array surface waves. On the other hand, the different nature of the seismic waves analysed with the different techniques (refracted wave in well logging versus dispersion of Rayleigh waves in the array techniques) can also cause a difference between the estimated shear-wave velocities.

\section{Conclusions}

We have used slim-well geophysical logging and passive seismic techniques to characterize the near surface in an area in Hontomin, Burgos, Spain. The study area is dominated by a shallow complex structure and carbonate rocks.

Slim well logging completes the depth record of old welllogging data with sonic data from the surface down to $400 \mathrm{~m}$ 
depth. This information, combined with the gamma-ray log, helps to refine geological interpretation of the first $400 \mathrm{~m}$. $P$-wave-velocity data delineate two significant changes with depth in the Upper Cretaceous materials: a high-velocity layer overlying a zone with velocity decrease with depth, and an interbedded sector with high and low velocities. For the propagation of a seismic wave, this sector is equivalent to a low-velocity layer. Below this layer, we find low-velocity sediments corresponding to the Utrillas (Low Cretaceous) formation.

$\mathrm{H} / \mathrm{V}$ technique enabled us to obtain a sediment thickness map of a complex near-surface area in a fast and affordable way. This methodology can produce good results in areas with scarcity of boreholes.

A shear-wave velocity profile up to $800 \mathrm{~m}$ is obtained with the array technique. Regarding the near surface, this profile maps a velocity inversion within the Upper Cretaceous that has been correlated to the presence of the high-velocity layer over the interbedded sector. The change from Upper to Lower Cretaceous sediments has not been delineated with this technique. Since FK and SPAC are based on different assumptions of the surface wave propagation, we have used both for quality control of the results.
As a first step, passive seismic methods combined with near-surface geophysical logging constitute a fast way of characterizing near-surface complexity. In general, passive seismic methods are suitable for areas with low signal-tonoise ratio or with logistical issues (e.g. without enough space for instrumentation setup or problems with seismic source regulations). In addition, these techniques are costeffective. $\mathrm{H} / \mathrm{V}$ is fast and cheap, suitable as a reconnaissance step. This technique can help to detect areas with strong variation in bedrock depth and obtain an estimation of this value with additional information. For detailed studies, active surface wave experiments are required in order to obtain shear-wave velocity for the near surface. The use of the array techniques to obtain shear-wave velocity information allows the investigation depth of these active seismic techniques to be increased. Techniques based on surface waves are also suitable in areas with inversion velocity such as the one in this paper, overcoming the limitation of refraction surveys. 


\section{Appendix A}

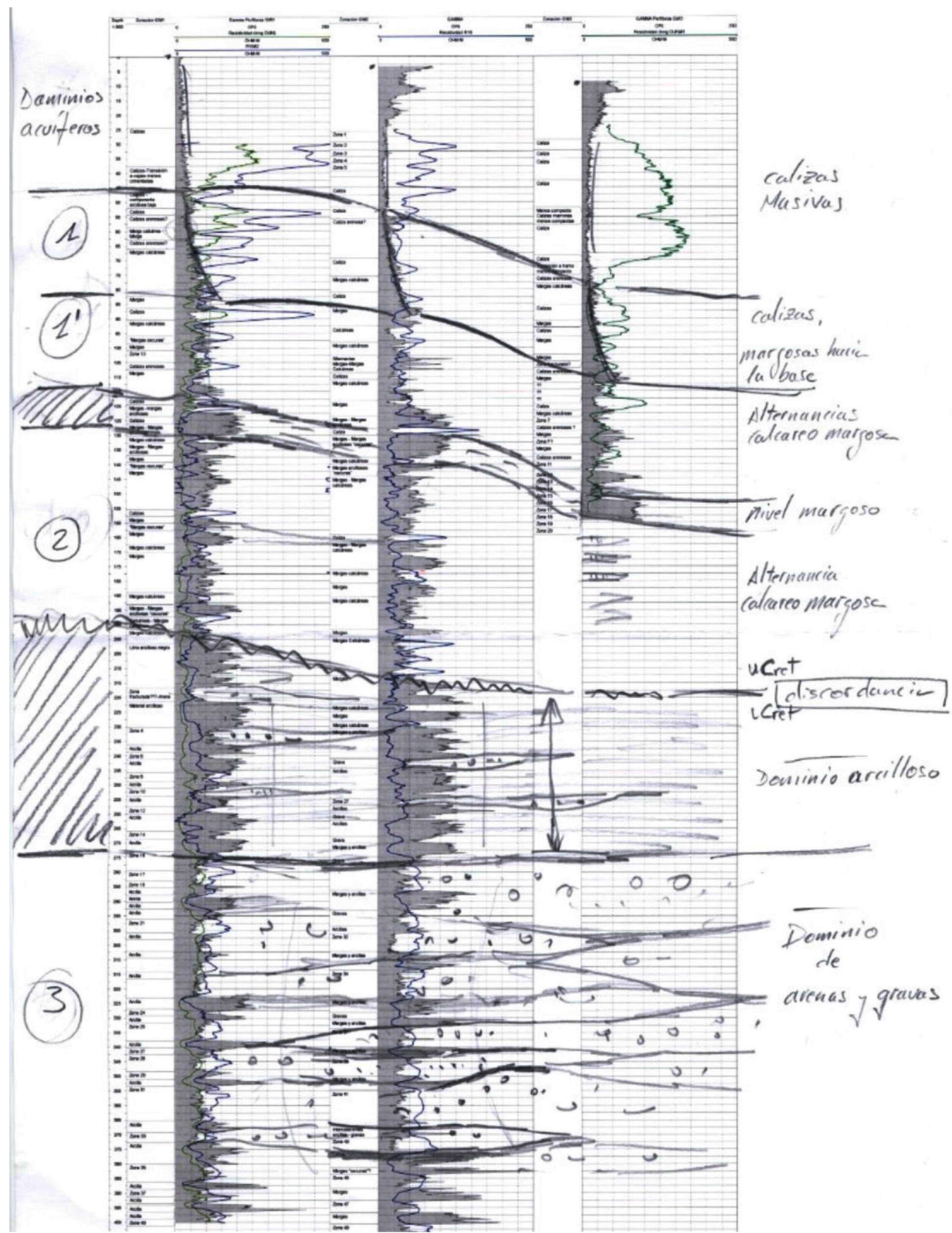

Figure A1. Natural gamma loggings from GW-1, GW-2 and GW-3 with the comments made by Andrés Pérez-Estaún. 
Author contributions. S. Figueras and A. Gabàs planned the field surveys for well logging and acquired the data from the GW-3 borehole. They also participated with comments and ideas for processing and interpretation. A. Macau planned the field surveys, acquired well-logging data from the GW-1 borehole, the passive seismic data sets and processed the $\mathrm{H} / \mathrm{V}$ and array data. He carried out the inversion of the dispersion and autocorrelation curves and interpretation of the shear-wave velocity models. B. Benjumea planned the field surveys, acquired well-logging data from GW-1 borehole and passive seismic data sets. She analysed the well-logging data and processed the sonic data sets. She interpreted the data sets and made the comparison between well-logging and passive seismic results. She prepared the manuscript with contributions from all co-authors.

Acknowledgements. We would like to thank Andrés Pérez-Estaún in memoriam for being the person who invited us to participate in this project. He contributed enthusiasm and wisdom to the interpretation of well-logging data (Appendix A).

We acknowledge all the people who have assisted in the field: I. Marzán, F. Bellmunt, E. Falgàs, J. Rovirò, M. Esquerda, J. Salvat and M. A. Romero. We thank the two referees for their helpful comments. This work has been partly funded by the Spanish Science and Innovation Ministry project PIER-CO2 (Progress In Electromagnetic Research for $\mathrm{CO}_{2}$ geological reservoirs CGL2009-07604).

Edited by: E. H. Rutter

\section{References}

Aki, K.: Space and time spectra of stationary stochastic waves, with special reference to microtremors, B. Earthq. Res. I. Tokyo, 35, 415-456, 1957.

Alcalde, J., Marzán, I., Saura, E., Martí, D., Ayarza, P., Juhlin, C., and Carbonell, R.: 3D geological characterization of the Hontomín $\mathrm{CO}_{2}$ storage site, Spain: Multidisciplinary approach from seismic, well-log and regional data, Tectonophysics, 627, 6-25, 2014.

Backus, G. E.: Long-wave elastic anisotropy produced by horizontal layering, J. Geophys. Res., 67, 4427-4440, 1962.

Bard, P. Y.: Microtremor measurements: a tool for site effect estimation?, in: The effects of surface geology on seismic motion-recent progress and new horizon on ESG study, edited by: Irikura, K., Kudo, K., Okada, H., and Sasatani, T., Balkema, Rotterdam, 3, 1251-1279, 1999.

Bard, P. Y. and SESAME-Team: Guidelines for the implementation of the $\mathrm{H} / \mathrm{V}$ spectral ratio technique on ambient vibrations-measurements, processing and interpretations, SESAME European research project EVG1-CT-200000026, deliverable D23.12, available at: http://sesame-fp5.obs. ujf-grenoble.fr, 2004.

Benjumea, B., Macau, A., Gabàs, A., Bellmunt, F., Figueras, S., and Cirés, J.: Integrated geophysical profiles and $\mathrm{H} / \mathrm{V}$ microtremor measurements for subsoil characterization, Near Surf. Geophys., 9, 413-425, 2011.

Bettig, B., Bard, P. Y., Scherbaum, F., Riepl, J., Cotton, F., Cornou, C., and Hatzfeld, D.: Analysis of dense array noise measurements using the modified spatial auto-correlation method (SPAC): application to the Grenoble area, B. Geofis. Teor. Appl., 42, 281304, 2001.

Bonnefoy-Claudet, S., Cotton, F., and Bard, P. Y.: The nature of noise wavefield and its applications for site effects studies: a literature review, Earth-Sci. Rev., 79, 205-227, 2006.

Box, R. and Lowrey, P.: Reconciling sonic logs with check-shot surveys: Stretching synthetic seismograms, The Leading Edge, 22, 510-517, 2003.

Bridle, R., Barsoukov, N., Al-Homaili, M., Ley, R., and Al-Mustafa, A.: Comparing state-of the art near-surface models of a seismic test line from Saudi Arabia, Geophys. Prospect., 54, 667-680, 2006.

Davis, J. C.: Statistics and Data Analysis in Geology, 3rd Edn., Wiley Ed., New York, 638 pp., 2002.

Delgado, J., López Casado, C., Giner, J., Estévez, A., Cuenca, A., and Molina, S.: Microtremors as a geophysical exploration tool: Applications and limitations, Pure Appl. Geophys., 157, 14451462, 2000.

Dvorkin, J., Walls, J., and Mavko, G.: Rock physics of marls, SEG Technical Program Expanded Abstracts 2001, 1784-1787, 2001.

Eberli, G. P., Baechle, G. T., Anselmetti, F. S., and Incze, M. L.: Factors controlling elastic properties in carbonate sediments and rocks, The Leading Edge, 22, 654-660, 2003.

Ellis, D. V. and Singer, J. M.: Well Logging for Earth Scientists, 2nd Edn., Springer, Dordrecht, the Netherlands, 691 pp., 2007.

Flecha, I., Carbonell, R., Hobbs, R. W., and Zeyen, H.: Some improvements in subbasalt imaging using pre-stack depth migration, Solid Earth, 2, 1-7, doi:10.5194/se-2-1-2011, 2011.

Gabàs, A., Macau, A., Benjumea, B., Bellmunt, F., Figueras, S., and Vilà, M.: Combination of geophysical methods to support urban geological mapping, Surv. Geophys., 35, 983-1002, 2014.

Horike, M.: Inversion of phase velocity of long-period microtremors to the $S$ wave-velocity structure down to the basement in urbanized areas, J. Phys. Earth, 33, 59-96, 1985.

Hovem, J. M.: Acoustic waves in finely layered media, Geophysics, 60, 1217-1221, 1995.

Ibs-Von Seht, M. and Wohlenberg, J.: Microtremor measurements used to map thickness of soft sediments, Bull. Seismol. Soc. Am., 89, 250-259, 1999.

IGME: Mapa Geológico de España a escala 1 : 50000 (Hoja N 167Montorio del Plan MAGNA), Instituto Geológico y Minero de España, 1997.

Kimball, C. V. and Marzetta, T. L.: Semblance processing of borehole acoustic array data, Geophysics, 49, 274-281, 1984.

Lermo, J. and Chávez-García, F. J.: Site effect evaluation using spectral ratios with only one station, Bull. Seism. Soc. Am., 83, 1574-1594, 1993.

Martini, F. and Bean, C. J.: Interface scattering versus body scattering in subbasalt imaging and application of prestack wave equation datuming, Geophysics, 67, 1593-1601, 2002.

Muñoz, J. A.: Evolution of a continental collision belt: ECORSPyrenees crustal balanced cross-section, in: Thrust Tectonics, edited by: McClay, K. R., Chapman \& Hall, London, 235-246, 1992.

Nakamura, Y.: A method for dynamic characteristics estimation of subsurface using microtremors on the ground surface, Q. Rep. Railway Tech. Res. Inst. Tokyo, 30, 25-33, 1989. 
Nogoshi, M. and Igarashi, T.: On the propagation characteristics estimations of subsurface using microtremors on the ground surface, J. Seism. Soc. Japan, 23, 264-280, 1970 (in Japanese with English abstract).

Ogaya, X., Queralt, P., Ledo, J., Marcuello, A., and Jones, A. G.: Geoelectrical baseline model of the subsurface of the Hontomín site (Spain) for $\mathrm{CO}_{2}$ geological storage in a deep saline aquifer: A 3D magnetotelluric characterisation, Int. J. Greenh. Gas Con., 27, 120-138, 2014.

Ogaya, X., Alcalde, J., Marzán, I., Ledo, J., Queralt, P., Marcuello, A., Martí, D., Saura, E., Carbonell, R., and Benjumea, B.: Joint interpretation of magnetotelluric, seismic and well-log data in Hontomín (Spain), Solid Earth Discuss., doi:10.5194/se-201624, in review, 2016.

Okada, H.: The microtremor survey method, Geophysical Monograph Series, Society of Exploration Geophysicists, 12, 97-116, 2003.

Paillet, F., Killeen, P., and Reeves, G.: Special issue-Non-petroleum applications of borehole geophysics-Preface, J. Appl. Geophys., $55,1-2,2004$.

Quesada, S., Robles, S., and Rosales, I.: Depositional architecture and transgressive-regressive cycles within Liassic backstepping carbonate ramps in the Basque-Cantabrian basin, northern Spain, J. Geol. Soc. London, 162, 531-538, 2005.
Quintà, A.: El patrón de fracturación alpina en el sector suroccidental de los Pirineos Vascos, Ph.D. Thesis, Univ. Barcelona, Barcelona, Spain, 153 pp., 2013.

Roca, E., Muñoz, J. A., Ferrer, O., and Ellouz, N.: The role of the Bay of Biscay Mesozoic extensional structure in the configuration of the Pyrenean orogen: constraints from the MARCONI deep seismic reflection survey, Tectonics, 30, TC2001, doi:10.1029/2010TC002735, 2011.

Serra, O. and Serra, L.: Well Logging Data Acquistion and Interpretation, Serra Log., Corbon, France, 674 pp., 2004.

Singh, S. and Kanli, A. I.: Estimating shear wave velocities in oil fields: a neural network approach, Geosci. J., 20, 221-228, 2016.

Stevens, J. L. and Day, S. M.: Shear velocity logging in slow formations using the Stoneley wave, Geophysics, 51, 137-147, 1986.

Stovas, A. and Ursin, B.: Equivalent time-average and effective medium for periodic layers, Geophys. Prospect., 55, 871-882, 2007.

Wathelet, M.: An improved neighborhood algorithm: parameter conditions and dynamic scaling, Geophys. Res. Lett., 35, L09301, doi:10.1029/2008GL033256, 2008.

Wathelet, M., Jongmans, D., Ohrnberger, M., and BonnefoyClaudet, S.: Array performances for ambient vibrations on a shallow structure and consequences over $\mathrm{V}_{\mathrm{S}}$ inversion, J. Seismol., 12, 1-19, 2008. 